\title{
Single Phase Cool White Light Emitting Novel Ca9Al(P04)7: Dy3+ Nanophosphor under NUV excitation
}

\section{Manju Dahiya}

Deenbandhu Chhotu Ram University of Science and Technology

Dinesh Kumar ( $\sim$ dineshdalal8@rediffmail.com )

Deenbandhu Chhotu Ram University of Science and Technology https://orcid.org/0000-0003-03434173

\section{Research Article}

Keywords: Rietveld Refinement, Solution-combustion, Scherrer Equation, Concentration Quenching, Chromaticity

Posted Date: February 11th, 2021

DOI: https://doi.org/10.21203/rs.3.rs-224262/v1

License: (c) (i) This work is licensed under a Creative Commons Attribution 4.0 International License. Read Full License 


\title{
Single Phase Cool White Light Emitting Novel Ca9Al( $\left(\mathrm{PO}_{4}\right)_{7}: \mathrm{Dy}^{3+} \mathrm{Nanophosphor}^{3}$ under NUV excitation
}

\author{
Manju Dahiya ${ }^{1}$, Dinesh Kumar ${ }^{1}$ \\ ${ }^{1}$ Department of chemistry, Deenbandhu Chhotu Ram University of Science and Technology, \\ Murthal, Sonepat-131039, India.
}

\begin{abstract}
A series of novel single-phase white light-emitting $\mathrm{Dy}^{3+}$ doped $\mathrm{Ca} 9 \mathrm{Al}\left(\mathrm{PO}_{4}\right)_{7}$ nanophosphors was successfully synthesized at $1100{ }^{\circ} \mathrm{C}$ via solution combustion route. X-ray diffraction (XRD) and Rietveld refinement analysis of $\mathrm{Ca}_{9} \mathrm{Dy}_{0.03} \mathrm{Al}_{0.97}\left(\mathrm{PO}_{4}\right)_{7}$ sample confirmed that this phosphor had a trigonal crystal structure with space group R3c(161). Meanwhile, as-observed from the transmission electron microscopy (TEM) study; particles of $\mathrm{Ca}_{9} \mathrm{Dy}_{x} \mathrm{Al}_{(1-x)}\left(\mathrm{PO}_{4}\right)_{7}$ samples were found to have a quadrilateral shape with crystallite sizes around 40-60 nm which were also confirmed by the Debye Scherrer equation. Under near-ultraviolet (NUV) excitation at $350 \mathrm{~nm}$, photoluminescence (PL) emission spectra of nanocrystalline $\mathrm{Ca} 9 \mathrm{Al}\left(\mathrm{PO}_{4}\right)_{7}: \mathrm{Dy}^{3+}$ phosphors showed two peaks at $481 \mathrm{~nm}$ and $572 \mathrm{~nm}$ corresponding to ${ }^{4} \mathrm{~F}_{9 / 2} \rightarrow{ }^{6} \mathrm{H}_{15 / 2}$ and ${ }^{4} \mathrm{~F}_{9 / 2} \rightarrow{ }^{6} \mathrm{H}_{13 / 2}$ transitions, respectively. The optimum concentration was found to be $x=0.03 \mathrm{~mol}$. The critical energy transfer distance was calculated to be 20 and further Huang analysis concluded the exact mechanism i.e. dipole-dipole interactions responsible for concentration quenching in $\mathrm{Ca}_{9} \mathrm{Dy}_{x} \mathrm{Al}_{(1-x)}\left(\mathrm{PO}_{4}\right)_{7}$ samples. Furthermore, the Commission Internationale de I'Eclairage (CIE) chromaticity coordinates of Ca9 $\mathrm{Dy}_{0.03} \mathrm{Al}_{0.97}\left(\mathrm{PO}_{4}\right)_{7}$ nanophosphor was calculated to be $(0.260,0.297)$ and this nanophosphor had correlated color temperature (CCT) of $11332 \mathrm{~K}$ which is located in a cool white area. Existing results indicate that $\mathrm{Ca}_{9} \mathrm{Dy}_{0.03} \mathrm{Al}_{0.97}\left(\mathrm{PO}_{4}\right)_{7}$ nanophosphor may be considered as a favorable candidate in NUV based single-phase cool White light-emitting diodes (WLEDs).
\end{abstract}

Keywords: Rietveld Refinement, Solution-combustion, Scherrer Equation, Concentration Quenching, Chromaticity.

Corresponding Author Tel: +919215744922

E-mail address: dineshdalal8@ rediffmail.com (Dinesh Kumar) 


\section{Introduction}

Nowadays, nano-scaled crystalline materials like rare-earth-doped luminescent nanophosphors are considered as the future generation lighting sources and components of future technology due to their unique features such as low power consumption, high energy efficiency, and long service life over the bulk materials [1-7]. Also, the nano size of particles reduces the non-radiative process and thus, increase the quantum efficiency [8,9]. These nanophosphors have major importance in the plasma display panel, field emission display, scintillations, solid-state laser, and white light-emitting diodes (WLEDs) [10-12]. In the current scenario, WLEDs have suppressed the traditional incandescent and fluorescent lamps due to their unique features such as economic or cost-effective, energy-efficient, low power consumption, and long service time. There are two methods to fabricate WLEDs i.e. the first method is by combining blue LED chip with yellow phosphors (YAG: $\mathrm{Ce}^{3+}$ ) but this method has several drawbacks such as low color rendering index (CRI) and high color temperature $[13,14]$. At present time, this method to fabricate WLEDs is considered as an existing method. The second method is by combining Red, Green, and Blue (RGB) phosphors with blue LED chips $[15,16]$. But reabsorption of the blue light by red and green phosphors decreases the conversion efficiency $[17,18]$. So the direct illumination of white light by a single component excited by a blue LED chip is the best alternation process to fabricate WLEDs as compared to the multi-components emitter. It is a simple and better reproducible fabrication approach [19-21].

In this respect, Dysprosium ion has been attracting the attention of researchers as Dy ${ }^{3+}$ ion activated inorganic phosphors are full-color phosphors which can be excited by the blue LED chips and its compounds show magnificent optical, magnetic, and electrical properties. For $\mathrm{Dy}^{3+}$ ions, luminescence peaks are produced in regions blue $(470-500 \mathrm{~nm})$ and yellow (570-650 nm) corresponding to the ${ }^{4} \mathrm{~F}_{9 / 2} \rightarrow{ }^{6} \mathrm{H}_{15 / 2}$ and ${ }^{4} \mathrm{~F}_{9 / 2} \rightarrow{ }^{6} \mathrm{H}_{13 / 2}$ transitions respectively. So by regulating the intensity ratio of yellow to blue emission, it is possible to obtain white light from $\mathrm{Dy}^{3+}$ activated compounds [22,23]. Also, the selection of the host matrix along with activator ions is a matter of consideration. Previously, many hosts doped with $\mathrm{Dy}^{3+}$ ion have been reported like $\mathrm{Y}_{2} \mathrm{SiO}_{5}, \mathrm{CaMoO}_{4}, \mathrm{Sr}_{4} \mathrm{Al}_{14} \mathrm{O}_{15}$, etc [24-26]. But Nowadays, inorganic phosphate compounds $\mathrm{A} 9 \mathrm{~B}\left(\mathrm{PO}_{4}\right)_{7}$ type where $\left(\mathrm{A}=\mathrm{Ca}^{2+}, \mathrm{Sr}^{2+}\right.$, and $\mathrm{B}=\mathrm{La}^{3+}, \mathrm{Y}^{3+}, \mathrm{Gd}^{3+}$, and $\mathrm{Al}^{3+}$ ions) have been widely attaining the limelight in the domain luminescent materials due to their rare optical properties, less sintering temperature, low cost of synthesis and high chemical stability, etc. $[23,27,28]$. Consequently, $\mathrm{Ca} 9 \mathrm{Al}\left(\mathrm{PO}_{4}\right)_{7}$ could be a good choice as a 
host matrix for fabricating rare-earth ions doped nanophosphors. From literature survey, some research articles such as $\mathrm{Ca} 9 \mathrm{Al}\left(\mathrm{PO}_{4}\right)_{7}: \mathrm{Eu}^{2+}$ by D.H and co-workers [29], $\mathrm{Ca} 9 \mathrm{Al}_{(}\left(\mathrm{PO}_{4}\right)_{7}$ : $\mathrm{Ce}^{3+}-\mathrm{Eu}^{3+}$ by Meng Xiang-yu and co-workers [30] and $\mathrm{Eu}^{3+}$ doped $\mathrm{Ca} 9 \mathrm{R}\left(\mathrm{PO}_{4}\right)_{7}(\mathrm{R}=\mathrm{Al}, \mathrm{Lu})$ by $\mathrm{F} \mathrm{Du}$ and co-workers [28] etc. have been reported and fabricated by high-temperature solid-state method of synthesis. This method is very time consuming. To the best of the author's knowledge, there is no previous research study on $\mathrm{Ca} 9 \mathrm{Al}\left(\mathrm{PO}_{4}\right)_{7}: \mathrm{Dy}^{3+}$ by any fabrication method reported so far. The author has attempted to synthesize novel $\mathrm{Ca} 9 \mathrm{Al}\left(\mathrm{PO}_{4}\right)_{7}: \mathrm{Dy}^{3+}$ nanophosphor by the solution combustion route at $1100{ }^{\circ} \mathrm{C}$. This method has numerous advantages over other traditional methods such as low temperature, less time consuming, and gives the homogeneous product [9,31]. X-ray diffraction (XRD) analysis was used to examine the purity of fabricated samples. Structural and morphological properties were studied with the help of Rietveld refinement analysis, and Transmission electron microscopy (TEM) techniques. The photoluminescent (PL) properties were thoroughly investigated to determine the emission and excitation region of as-synthesized samples. Lastly, Commission international de I'Eclairage (CIE) color and Correlated color temperature (CCT) coordinates were also calculated which showed that as-obtained nanophosphors might have practical applicability in single-phase WLEDs.

\section{Experimental section}

\subsection{Materials and Synthesis}

A series of rare-earth-doped nanocrystalline $\mathrm{Ca}_{9} \mathrm{Dy}_{x} \mathrm{Al}_{(1-x)}\left(\mathrm{PO}_{4}\right)_{7}$ (where $x=0-0.15$ mol) powdered phosphors was fabricated by employing a highly efficient and time-savvy solution combustion route. The calculated amounts of raw materials bought from Sigma Aldrich such as Calcium nitrate tetrahydrate $\left(\mathrm{Ca}\left(\mathrm{NO}_{3}\right)_{2} .4 \mathrm{H}_{2} \mathrm{O}\right)$, Aluminum nitrate nonahydrate $\left(\mathrm{Al}\left(\mathrm{NO}_{3}\right)_{3} .9 \mathrm{H}_{2} \mathrm{O}\right)$, Dysprosium nitrate hydrate $\left(\mathrm{Dy}\left(\mathrm{NO}_{3}\right)_{3} . \mathrm{H}_{2} \mathrm{O}\right)$, di-Ammonium hydrogen phosphate $\left(\left(\mathrm{NH}_{4}\right)_{2} \mathrm{HPO}_{4}\right)$ and urea $\left(\mathrm{NH}_{2} \mathrm{CONH}_{2}\right)$ were used without performing further purification. All the precursors were dissolved in a minimum amount of doubledistilled water taken in a $500 \mathrm{ml}$ beaker. The stoichiometric amount of urea as fuel was calculated based on oxidizing and reducing valency of oxidizer and fuel [32]. The solution was concentrated by heating on a hot plate until excess water evaporated, and this concentrated solution was then transferred into a preheated muffle furnace maintained at 500 ${ }^{\circ} \mathrm{C}$ for $10-15$ minutes. In beginning, the solution undergoes rapid dehydration with the liberation of a huge amount of gaseous by-products such as the nitrogen and oxides of 
carbon. The volatile gases burn with a flame producing a dried solid mass. Then the dried solid product was crushed using agate mortar-pestle to get fine powder which was finally sintered at $1100{ }^{\circ} \mathrm{C}$ for about 3 hours. The combustion synthesis of $\mathrm{Ca} 9 \mathrm{Dy}_{0.03} \mathrm{Al}_{0.97}\left(\mathrm{PO}_{4}\right)_{7}$ nanophosphor is represented by a given chemical reaction:

$300 \mathrm{Ca}\left(\mathrm{NO}_{3}\right)_{2} .4 \mathrm{H}_{2} \mathrm{O}+32.333 \mathrm{Al}\left(\mathrm{NO}_{3}\right)_{3} .9 \mathrm{H}_{2} \mathrm{O}+\mathrm{Dy}\left(\mathrm{NO}_{3}\right)_{3} \cdot \mathrm{H}_{2} \mathrm{O}+233.333\left(\mathrm{NH}_{4}\right)_{2} \mathrm{HPO} 4+$ $3591 \mathrm{NH}_{2} \mathrm{CONH}_{2} \rightarrow 33.333 \mathrm{Ca} 9 \mathrm{Dy}_{0.03} \mathrm{Al}_{0.97}\left(\mathrm{PO}_{4}\right)_{7}+4174.333 \mathrm{~N}_{2}+9723 \mathrm{H}_{2}+3591 \mathrm{CO}_{2}$

\subsection{Characterization techniques}

The crystal phase of $\mathrm{Ca} 9 \mathrm{Al}\left(\mathrm{PO}_{4}\right)_{7}: \mathrm{Dy}^{3+}$ phosphor has been confirmed by using a high-resolution "Rigaku Ultima-IV X-ray diffractometer" having $\mathrm{Cu}-\mathrm{K}_{\alpha}$ radiations operating at $40 \mathrm{kV}$ and $40 \mathrm{~mA}$ voltage and tube current, respectively. The samples were scanned from $2 \theta=10^{\circ}$ to $80^{\circ}$ at a constant scanning rate of $2^{\circ}$ per minute. The structure elucidation and determination of lattice parameters of as-synthesized $\mathrm{Ca}_{9} \mathrm{Dy}_{0.03} \mathrm{Al}_{0.97}\left(\mathrm{PO}_{4}\right)_{7}$ sample calcined at 1100 'C was done using "GSAS (General Structure Analysis System) program". The morphology of Ca9Dy0.03 $\mathrm{Al}_{0.97}\left(\mathrm{PO}_{4}\right)_{7}$ was studied by "Technai $\mathrm{G}^{2}$ transmission electron microscope (TEM)”." Hitachi F-7000 fluorescence spectrophotometer” fitted with Xe lamp as an excitation source of light was used to study the optical properties of $\mathrm{Ca}_{9} \mathrm{Dy}_{x} \mathrm{Al}_{(1-x)}\left(\mathrm{PO}_{4}\right)_{7}$ $(x=0.01-0.15 \mathrm{~mol})$ nanophosphors. The width of the slit which was used to study excitation and emission was set at $2.5 \mathrm{~nm}$. The voltage of the photomultiplier tube was also set at $40 \mathrm{~V}$. The whole procedure was performed at room temperature.

\section{Result and discussion}

\subsection{Structural Analysis}

In the present study, we have synthesized $\mathrm{Ca} 9 \mathrm{Al}\left(\mathrm{PO}_{4}\right)_{7}: \mathrm{Dy}^{3+}$ using solution combustion method and XRD pattern of as-synthesized $\mathrm{Ca}_{9} \mathrm{Dy}_{x} \mathrm{Al}_{(1-x)}\left(\mathrm{PO}_{4}\right)_{7}$ (where $x=0-$ $0.15 \mathrm{~mol}$ ) phosphors along with standard JCPDS data is shown in Fig. 1. It is well depicted from the X-ray diffractogram that all the profile peaks are in good agreement with the JCPDS data of the host which further concludes that the activator $\mathrm{Dy}^{3+}$ ions are doped homogenously in the host $\mathrm{Ca} 9 \mathrm{Al}\left(\mathrm{PO}_{4}\right)_{7}$ lattice. Through the use of the XRD pattern of $\mathrm{Ca}_{9} \mathrm{Dy}_{0.03} \mathrm{Al}_{0.97}\left(\mathrm{PO}_{4}\right)_{7}$ phosphor, Rietveld refinement using GSAS (General Structure Analysis System) software is executed to determine the crystal structure and unit cell parameters. Fig. 2 portrays the Rietveld refinement of $\mathrm{Ca}_{9} \mathrm{Dy}_{0.03} \mathrm{Al}_{0.97}\left(\mathrm{PO}_{4}\right)_{7}$ where the solid red line represents the calculated diffraction pattern and the observed diffraction profile is shown by a black 
diamond. The difference between calculated and observed diffraction patterns is shown by the blue line which is lying just above $\mathrm{X}$-axis. Lattice parameters of $\mathrm{Ca}$ 9 $\mathrm{Dy}_{0.03} \mathrm{Al}_{0.97}\left(\mathrm{PO}_{4}\right)_{7}$ phosphor as-obtained by the Rietveld refinement are as $a=b=10.44 \AA, c=37.38 \AA$, and $\alpha=$ $\beta=\gamma=90^{\circ}, \mathrm{V}=3432.63 \AA^{3}$, and $\mathrm{Z}=6$ which are quite similar with the data published in previous reports of the host [33]. The Rietveld refinement of $\mathrm{Ca}_{9} \mathrm{Dy}_{0.03} \mathrm{Al}_{0.97}\left(\mathrm{PO}_{4}\right)_{7}$ phosphor confirms the occurrence of its crystal structure into a trigonal shape having R3c(161) space group. Table 1 shows the comparison of crystal structure data of $\mathrm{Ca}_{9} \mathrm{Dy}_{0.03} \mathrm{Al}_{0.97}\left(\mathrm{PO}_{4}\right)_{7}$ phosphor with that to the host $\mathrm{Ca} 9 \mathrm{Al}\left(\mathrm{PO}_{4}\right)_{7}$ [30]. All these results reveal that $\mathrm{Dy}^{3+}$ ions can easily replace $\mathrm{Al}^{3+}$ ions without changing its crystal prototype. A very little increase in the volume of the unit cell is observed when $\mathrm{Dy}^{3+}$ ions are doped into $\mathrm{Ca} 9 \mathrm{Al}\left(\mathrm{PO}_{4}\right)_{7}$ host lattice which may be due to the larger radius of $\mathrm{Dy}^{3+}$ ion than $\mathrm{Al}^{3+}$ ion. The complete crystal structure of $\mathrm{Ca}_{9} \mathrm{Dy}_{0.03} \mathrm{Al}_{0.97}\left(\mathrm{PO}_{4}\right)_{7}$ which is constituting of the $\mathrm{PO}_{4}, \mathrm{CaO}_{8}$, and $\mathrm{Al} / \mathrm{DyO}_{6}$ polyhedral units, and the coordination environment around different cations are shown in Fig. 3.

Furthermore, the average crystallite size $(D)$ of $\mathrm{Ca}_{9} \mathrm{Dy}_{x} \mathrm{Al}_{(1-x)}\left(\mathrm{PO}_{4}\right)_{7}(x=0.01-0.15$ mol) samples is determined by a well known the Debye-Scherer's equation [34,35]:

$$
D=\frac{0.941 \lambda}{\beta \cos \theta}
$$

Where $\lambda$ shows the wavelength of $\mathrm{X}$-ray radiations used $(0.15406 \mathrm{~nm}), \theta$ be the diffraction angle and $\beta$ shows full width at half maximum (FWHM). From the Scherrer equation, the crystallite sizes come out to be 40-60 nm. The TEM image of Ca9Dy0.03Alo.97 $\left(\mathrm{PO}_{4}\right)_{7}$ sample also shows an average crystal size around $50-60 \mathrm{~nm}$ as shown in Fig. 4. The strain $(\varepsilon)$ and dislocation density $(\delta)$ are also determined for all the synthesized nanophosphors using the following equations, respectively [36,37]:

$$
\begin{gathered}
\varepsilon=\frac{\beta \cos \theta}{4} \\
\delta=\frac{1}{D^{2}}
\end{gathered}
$$

The results thus obtained from the above-mentioned equations are tabulated in Table 2. 


\subsection{Photoluminescent properties}

Fig. 5 displays the photoluminescent excitation (PLE) spectrum of $\mathrm{Ca}_{9} \mathrm{Dy}_{x} \mathrm{Al}_{(1-}$ ${ }_{x)}\left(\mathrm{PO}_{4}\right)_{7}(x=0.01-0.15 \mathrm{~mol})$ nanophosphor monitored at $572 \mathrm{~nm}$ which contains distinct sharp peaks at $326,350,364,387,426,452$, and $473 \mathrm{~nm}$ corresponding to ${ }^{6} \mathrm{H}_{15 / 2} \rightarrow{ }^{6} \mathrm{P}_{3 / 2}$, ${ }^{6} \mathrm{H}_{15 / 2} \rightarrow{ }^{6} \mathrm{P}_{3 / 2},{ }^{6} \mathrm{H}_{15 / 2} \rightarrow{ }^{6} \mathrm{P}_{5 / 2}, \quad{ }^{6} \mathrm{H}_{15 / 2} \rightarrow{ }^{6} \mathrm{I}_{13 / 2}, \quad{ }^{6} \mathrm{H}_{15 / 2} \rightarrow{ }^{4} \mathrm{G}_{11 / 2}, \quad{ }^{6} \mathrm{H}_{15 / 2} \rightarrow{ }^{4} \mathrm{I}_{15 / 2}$, and ${ }^{6} \mathrm{H}_{15 / 2} \rightarrow{ }^{4} \mathrm{~F}_{9 / 2}$ transitions, respectively [37,38]. The peak located at $350 \mathrm{~nm}$ has the highest intensity in the excitation spectra of nanophosphors. Thereby, the emission spectra of the whole series are recorded at the excitation wavelength $(350 \mathrm{~nm})$. From the excitation properties, it is concluded that $\mathrm{Ca}_{9} \mathrm{Dy}_{x} \mathrm{Al}_{(1-x)}\left(\mathrm{PO}_{4}\right)_{7}(x=0.01-0.15 \mathrm{~mol})$ nanophosphors may be excited by NUV LED chips. Fig. 6 represents the PL emission spectra of $\mathrm{Ca}_{9} \mathrm{Dy}_{x} \mathrm{Al}_{(1-x)}\left(\mathrm{PO}_{4}\right)_{7}(x=0.01-$ $0.15 \mathrm{~mol}$ ) nanophosphor samples which contain two intense peaks in the blue and yellow region at $481 \mathrm{~nm}$ and $572 \mathrm{~nm}$ corresponding to ${ }^{4} \mathrm{~F}_{9 / 2} \rightarrow{ }^{6} \mathrm{H}_{15 / 2}$, and ${ }^{4} \mathrm{~F}_{9 / 2} \rightarrow{ }^{6} \mathrm{H}_{13 / 2}$ transitions, respectively $[23,39]$.

Besides, it is generally known that the PL properties of $\mathrm{Dy}^{3+}$ doped matrices are affected by the crystal field environment of the host matrix. When $\mathrm{Dy}^{3+}$ ions are situated at low symmetric sites, then yellow emission $\left({ }^{4} \mathrm{~F}_{9 / 2} \rightarrow{ }^{6} \mathrm{H}_{13 / 2}\right)$ is dominant, while blue emission $\left({ }^{4} \mathrm{~F}_{9 / 2} \rightarrow{ }^{6} \mathrm{H}_{13 / 2}\right)$ is prominent when Dy ${ }^{3+}$ ions are located at high symmetry sites $[39,40]$. In our experimental work, the blue emission peak at $481 \mathrm{~nm}$ is stronger than the yellow emission peak at $572 \mathrm{~nm}$ for each sample which ultimately confirmed that the dopant $\mathrm{Dy}^{3+}$ ions are situated at high symmetric sites into the host $\left(\mathrm{Ca} 9 \mathrm{Al}\left(\mathrm{PO}_{4}\right)_{7}\right)$ matrix.

Further, the relative intensity ratio of the yellow to blue emission i.e. Y/B ratio is calculated to determine the distortion of structure around $\mathrm{Dy}^{3+}$ ions. Y/B ratio is calculated for the whole series $\mathrm{Ca}_{9} \mathrm{Dy}_{x} \mathrm{Al}_{(1-x)}\left(\mathrm{PO}_{4}\right)_{7}(x=0.01-0.15 \mathrm{~mol})$ by the given relation $[41,42]$ :

$$
\frac{Y}{B}=\frac{\int_{550}^{600} I_{2}}{\int_{450}^{500} I_{1}}
$$

The calculated Y/B values of $\mathrm{Ca}_{9} \mathrm{Dy}_{x} \mathrm{Al}_{(1-x)}\left(\mathrm{PO}_{4}\right)_{7}(x=0.01-0.15 \mathrm{~mol})$ phosphors are reported in Table 3 and it is well depicted that $\mathrm{Y} / \mathrm{B}$ values do not show significant change with the increase in the concentration of $\mathrm{Dy}^{3+}$ ions, which means dopant ions are located in high symmetrical sites and electric dipole transitions dominate [23]. 


\subsection{Concentration quenching}

The variation of PL intensity with an increase in the concentration of dopant ions is depicted in Fig. 7. Initially, PL intensity increases with an increase in the concentration of $\mathrm{Dy}^{3+}$ ions up to 0.03 mol which is known as the optimum concentration, and then the intensity falls gradually with further increase in the concentration of dopant ions due to the concentration quenching phenomenon. The main factor responsible for the concentration quenching phenomenon is generally the non-radiative energy transfer occurring between the neighboring dopant ions which are ascribed to be radiative reabsorption, exchange interaction, or multipole-multipole interaction $[37,43]$. The exact mechanism responsible for the quenching behavior is determined by calculating the critical (energy transfer) distance $\mathrm{R}_{\mathrm{c}}$ making use of the Blasse equation which is given below [36,44]:

$$
R_{c}=2\left[\frac{3 \mathrm{~V}}{4 \Pi \mathrm{N} x_{c}}\right]^{1 / 3}
$$

Where $\mathrm{V}$ represents the volume of a unit cell, $\mathrm{N}$ no. of the replaceable atom, and $x_{c}$ is critical concentration. By putting the values of $\mathrm{V}=3528 \AA^{3}, x_{c}=0.03$, and $\mathrm{N}=6$ in the above equation, the value of $R_{c}$ comes out to be around $20 \AA$ which is much greater than $5 \AA$, which means the possibility of the exchange interaction mechanism is eliminated. Also, the radiation reabsorption mechanism is not considered here because this mechanism needs an overlapping between PL spectra of activator $\mathrm{Dy}^{3+}$ ions and we don't get any spectral overlap while analyzing the PL properties of $\mathrm{Ca} 9 \mathrm{Al}\left(\mathrm{PO}_{4}\right)_{7}: \mathrm{Dy}^{3+}$ nanophosphors. Hence, the only mechanism responsible for the non-radiative energy transfer process is multipole-multipole interactions and the exact type of electric multipolar interactions can be determined by employing Huang analysis which correlates PL intensity with concentration as per the following relationship $[27,40]$ :

$$
\log \left(\frac{I}{x}\right)=-\left(\frac{s}{d}\right) \log x+\log (f)
$$

where $x$ stands for concentration of dopant ions greater than critical concentration, $f$ is a constant which is unaffected by the concentration of activator ion, $d$ is dimension of samples whose value is 3 and $s$ is the constant related to multipolar interaction constant which may be equal to 6, 8, and 10 for dipole-dipole (d-d), dipole-quadrupole (q-d), and quadrupole- 
quadrupole (q-q) interaction, respectively. The plot of $\log (I / x)$ vs $\log x$ known as Huang plot is a straight-line graph giving a slope value $1.6 \approx 2$ and hence the value of $s$ comes approximately 6 which concludes that the phenomenon responsible for concentration quenching is dipole-dipole interactions and three possible cross-relaxation channels among $\mathrm{Dy}^{3+}$ are shown in Fig. 9, represented as CRC1, CRC2 and CRC3. The $\mathrm{Dy}^{3+}$ ions at ${ }^{4} \mathrm{~F} 9 / 2$ level can be de-excited to $\left({ }^{6} \mathrm{~F}_{9 / 2} /{ }^{6} \mathrm{H}_{7 / 2}\right),\left({ }^{6} \mathrm{H}_{9 / 2} /{ }^{6} \mathrm{~F}_{11 / 2}\right)$ or ${ }^{6} \mathrm{~F}_{1 / 2}$ level via these three cross-relaxation processes, in the meanwhile the $\mathrm{Dy}^{3+}$ ions present in ground state by accepting the energies from the Dy ${ }^{3+}$ at ${ }^{4} \mathrm{~F}_{9 / 2}$ level will arrive at ${ }^{6} \mathrm{~F}_{3 / 2},{ }^{6} \mathrm{~F}_{5 / 2}$ and $\left({ }^{6} \mathrm{H}_{9 / 2} /{ }^{6} \mathrm{~F}_{11 / 2}\right)$ level. Finally, all the $\mathrm{Dy}^{3+}$ ions involved in CRC1, CRC2 and CRC3 processes will arrive in their ground states without radiative transitions, thus the luminescence related to ${ }^{4} \mathrm{~F}_{9 / 2}$ level are quenched [45]. Fig. 9 displays the schematic energy level diagram for $\mathrm{Dy}^{3+}$ ions.

\subsection{Decay time}

Lifetime decay curves are also analyzed and revealed mono-exponential behavior of decay curves of synthesized $\mathrm{Ca}_{9} \mathrm{Al}_{(1-x)}\left(\mathrm{PO}_{4}\right)_{7}: x \mathrm{Dy}^{3+}(x=0.01-0.15 \mathrm{~mol})$ by utilizing the following equation [46]:

$$
I=I_{o} \exp \left(-\frac{t}{\tau}\right)
$$

Where $ح$ corresponds to the radiative decay lifetime foe emission, $I$ and $I O$ are PL intensities at time $t$, and 0 , respectively. The mono-exponential nature of the decay curve shows the uniform distribution of dopant ions in the host matrix. The fluorescence decay time decreases from $0.69 \mathrm{~ms}$ to $0.52 \mathrm{~ms}$ with an increase in the concentration of $\mathrm{Dy}^{3+}$ ions. This may be due to a decrease in the average distance between dopant ions and an increase in non-radiative transitions. Lifetime values at different concentrations of dopant ions are shown in table 3 and the decay curve of $\mathrm{Ca}_{9} \mathrm{Dy}_{0.03} \mathrm{Al}_{0.97}\left(\mathrm{PO}_{4}\right)_{7}$ phosphor is represented in Fig. 10.

\subsection{CIE Chromaticity Coordinates}

CIE chromaticity diagram is used to determine the emission color of phosphors. CIE chromaticity coordinates of $\mathrm{Ca}_{9} \mathrm{Dy}_{x} \mathrm{Al}_{(1-x)}\left(\mathrm{PO}_{4}\right)_{7} \quad(x=0.01-0.15 \mathrm{~mol})$ were calculated using MATLAB software as shown in table 4 which are found to be identical with National television System Committee (NTSC) coordinates for white color emission [35]. Fig. 11 shows the $(x, y)$ coordinates of $\mathrm{Ca}_{9} \mathrm{Dy}_{0.03} \mathrm{Al}_{0.97}\left(\mathrm{PO}_{4}\right)_{7}$ nanophosphor with a black dot lie in the 
white region and it is suggested that this phosphor shows its potential utility in solid-state lighting devices and especially in single-phase WLEDs.

Further, CCT values are also evaluated by using CIE coordinates. CCT values tell about the color temperature of the light source which is measured in Kelvin. CCT for the whole series are calculated by using the McCammy Empirical formula as shown below $[47,48]$ :

$$
C C T=-437 n^{3}+3601 n^{2}-6861 n+5514.31
$$

Where $\mathrm{n}=\left(\frac{x-x e}{y-y e}\right)$ is inverse slope line, $x_{\mathrm{e}}=0.3320, y_{\mathrm{e}}=0.1858$ are epicenter and $x, y$ are CIE coordinates of phosphor. If CCT values come out greater than $4000 \mathrm{~K}$ then phosphor is considered as a cool light source and if these come to less than $3200 \mathrm{~K}$ then it is labeled as a warm light source. CCT values of $\mathrm{Ca} 9 \mathrm{Al}\left(\mathrm{PO}_{4}\right)_{7}: \mathrm{Dy}^{3+}$ come out greater than $4000 \mathrm{~K}$. So these are considered as cool light sources. u' and v' coordinates were also calculated using the following equations [49]:

$$
\begin{aligned}
& u^{\prime}=\frac{4 x}{-2 x+12 y+3} \\
& v^{\prime}=\frac{9 y}{-2 x+12 y+3}
\end{aligned}
$$

All the evaluated values for the whole series of CIE coordinates, CCT, and $\left(\mathrm{u}^{\prime}, \mathrm{v}^{\prime}\right)$ coordinates are depicted in table 4 and the CCT diagram of Ca9Dy0.03Al0.97 $\left(\mathrm{PO}_{4}\right)_{7}$ nanophosphor is displayed in Fig. 12.

\section{Conclusion}

A series of single-phase full color $\mathrm{Dy}^{3+}$ doped $\mathrm{Ca} 9 \mathrm{Al}\left(\mathrm{PO}_{4}\right)_{7}$ nanophosphors were synthesized for the first time by solution combustion method at $1100{ }^{\circ} \mathrm{C}$. Rietveld analysis of XRD data of $\mathrm{Ca}_{9} \mathrm{Dy}_{0.03} \mathrm{Al}_{0.97}\left(\mathrm{PO}_{4}\right)_{7}$ revealed the occurrence of different cations into a trigonal shaped crystal lattice structure with R3c(161) space symmetry. The PL emission spectral report disclosed the presence of two emission peaks in the blue and yellow region at 481 and $572 \mathrm{~nm}$, respectively under NUV excitation of $350 \mathrm{~nm}$. Concentration quenching occurred after $x=0.03 \mathrm{~mol}$ and the critical transfer distance was found to be $20 \AA$. The phenomenon responsible for concentration quenching has been established to be dipole-dipole interactions. The decay curves were well fitted and showed mono-exponential behavior. The observed 
intrinsic decay time $(0.697 \mathrm{~ms})$, non-radiative rate $\left(132 \mathrm{~s}^{-1}\right)$, quantum efficiency $(91.8 \%)$, CIE color coordinates $(0.260,0.297)$, and $\mathrm{CCT}(11332 \mathrm{~K})$ of $\mathrm{Ca}_{90} \mathrm{Dy}_{0.03} \mathrm{Al}_{0.97}\left(\mathrm{PO}_{4}\right)_{7}$ nanophosphor conclude that this novel full-color nanophosphor has superior luminescence properties and hence, $\mathrm{Ca}_{9} \mathrm{Dy}_{0.03} \mathrm{Al}_{0.97}\left(\mathrm{PO}_{4}\right)_{7}$ nanophosphor can be significantly used as a promising material in NUV based single-phase WLEDs or other display devices.

\section{Acknowledgment}

One of the authors, Manju Dahiya is thankful for financial help in the form of a senior research fellowship from the Council of Scientific and Industrial Research, India (CSIR), New Delhi, India (Award No. 09/1063/0014/2017-EMR-I).

\section{References}

1. C. J. Humphreys, MRS Bull. 33, 459 (2008).

2. P. You, G. Yin, X. Chen, B. Yue, Z. Huang, X. Liao, and Y. Yao, Opt. Mater. (Amst). 33, 1808 (2011).

3. H. A. Höppe, Angew. Chemie - Int. Ed. 48, 3572 (2009).

4. M. R. Krames, O. B. Shchekin, R. Mueller-Mach, G. O. Mueller, L. Zhou, G. Harbers, and M. G. Craford, IEEE/OSA J. Disp. Technol. 3, 160 (2007).

5. D. A. Steigerwald, J. C. Bhat, D. Collins, R. M. Fletcher, M. O. Holcomb, M. J. Ludowise, P. S. Martin, and S. L. Rudaz, IEEE J. Sel. Top. Quantum Electron. 8, 310 (2002).

6. Q. Zhang, C. S. Dandeneau, X. Zhou, and C. Cao, Adv. Mater. 21, 4087 (2009).

7. E. F. Schubert and J. K. Kim, Science (80-. ). 308, 1274 (2005).

8. M. Dalal, V. B. Taxak, S. Chahar, J. Dalal, A. Khatkar, and S. P. Khatkar, J. Alloys Compd. 686, 366 (2016).

9. S. Chahar, V. B. Taxak, M. Dalal, S. Singh, and S. P. Khatkar, Mater. Res. Bull. 77, (2016). 
10. A. Hooda, S. P. Khatkar, A. Khatkar, R. K. Malik, J. Dalal, S. Devi, and V. B. Taxak, Mater. Chem. Phys. 232, 39 (2019).

11. N. C. George, K. A. Denault, and R. Seshadri, Annu. Rev. Mater. Res. 43, 481 (2013).

12. S. Devi, V. B. Taxak, S. Chahar, M. Dalal, J. Dalal, A. Hooda, A. Khatkar, R. K. Malik, and S. P. Khatkar, Ceram. Int. 45, 15571 (2019).

13. Z. Yang, D. Xu, J. Sun, J. Du, and X. Gao, Mater. Sci. Eng. B Solid-State Mater. Adv. Technol. 211, 13 (2016).

14. D. Y. Wang, C. H. Huang, Y. C. Wu, and T. M. Chen, J. Mater. Chem. 21, 10818 (2011).

15. H. Xiao, Z. Xia, L. Liao, J. Zhou, and J. Zhuang, J. Alloys Compd. 534, 97 (2012).

16. J. Zhang, X. Zhang, M. Gong, J. Shi, L. Yu, C. Rong, and S. Lian, Mater. Lett. 79, 100 (2012).

17. R. J. Xie, N. Hirosaki, M. Mitomo, K. Sakuma, and N. Kimura, Appl. Phys. Lett. 89, 86 (2006).

18. Z. Xia, X. Wang, Y. Wang, L. Liao, and X. Jing, Inorg. Chem. 50, 10134 (2011).

19. Y. Song, G. Jia, M. Yang, Y. Huang, H. You, and H. Zhang, Appl. Phys. Lett. 94, 2007 (2009).

20. N. Guo, H. You, Y. Song, M. Yang, K. Liu, Y. Zheng, Y. Huang, and H. Zhang, J. Mater. Chem. 20, 9061 (2010).

21. H. A. Höppe, M. Daub, and M. C. Bröhmer, Chem. Mater. 19, 6358 (2007).

22. V. R. Bandi, B. K. Grandhe, H. J. Woo, K. Jang, D. S. Shin, S. S. Yi, and J. H. Jeong, J. Alloys Compd. 538, 85 (2012).

23. Z. W. Zhang, A. J. Song, Y. Yue, H. Zhong, X. Y. Zhang, M. Z. Ma, and R. P. Liu, J. Alloys Compd. 650, 410 (2015).

24. S. Dutta, S. Som, and S. K. Sharma, J. Chem. Soc. Dalt. Trans. 42, 9654 (2013).

25. Y. Lin, Z. Tang, Z. Zhang, and C. W. Nan, Appl. Phys. Lett. 81, 996 (2002).

26. N. Ishiwada, E. Fujii, and T. Yokomori, J. Lumin. 196, 492 (2018). 
27. J. Dalal, M. Dalal, S. Devi, A. Hooda, A. Khatkar, V. B. Taxak, and S. P. Khatkar, J. Lumin. 216, 116697 (2019).

28. F. Du, Y. Nakai, T. Tsuboi, Y. Huang, and H. J. Seo, J. Mater. Chem. 21, 4669 (2011).

29. Đ. O. H, H a $n$ g $Y$, and $H$ a $n$ g $K$, (n.d.).

30. X. yu Meng, X. Jie, Y. dong Zhang, D. Wang, Y. bin Wang, P. lai Li, Z. jun Wang, L. bin Pang, and S. jie Gao, Optoelectron. Lett. 11, 45 (2015).

31. M. Dalal, V. B. Taxak, J. Dalal, A. Khatkar, S. Chahar, R. Devi, and S. P. Khatkar, J. Alloys Compd. 698, 662 (2017).

32. H. Dahiya, M. Dalal, A. Siwach, M. Dahiya, V. B. Taxak, S. P. Khatkar, and D. Kumar, J. Mater. Sci. Mater. Electron. (2019).

33. R. Pạzik, K. Zawisza, A. Watras, K. Maleszka-Bagińska, P. Boutinaud, R. Mahiou, and P. J. Dereń, Mater. Res. Bull. 48, 337 (2013).

34. Q. Y. Zhang and X. Y. Huang, Prog. Mater. Sci. 55, 353 (2010).

35. P. Sehrawat, A. Khatkar, P. Boora, M. Kumar, S. Singh, R. K. Malik, S. P. Khatkar, and V. B. Taxak, Mater. Manuf. Process. 00, 1 (2020).

36. H. Dahiya, M. Dalal, J. Dalal, V. B. Taxak, S. P. Khatkar, and D. Kumar, Mater. Res. Bull. 99, (2018).

37. A. Hooda, S. P. Khatkar, A. Khatkar, S. Chahar, S. Devi, J. Dalal, and V. B. Taxak, Curr. Appl. Phys. 19, 621 (2019).

38. Y. XUE, F. XIAO, Q. ZHANG, and Z. JIANG, J. Rare Earths 27, 753 (2009).

39. L. Yang, Z. Mu, S. Zhang, Q. Wang, D. Zhu, Y. Zhao, D. Luo, Q. Zhang, and F. Wu, J. Mater. Sci. Mater. Electron. 29, 6548 (2018).

40. Y. Tian, B. Chen, B. Tian, R. Hua, J. Sun, L. Cheng, H. Zhong, X. Li, J. Zhang, Y. Zheng, T. Yu, L. Huang, and Q. Meng, J. Alloys Compd. 509, 6096 (2011).

41. A. R. Beck, S. Das, and J. Manam, J. Mater. Sci. Mater. Electron. 28, 17168 (2017).

42. L. Han, G. Liu, X. Dong, J. Wang, X. Wang, and Y. Yang, J. Mater. Sci. Mater. Electron. 
28, 16519 (2017).

43. A. Siwach, M. Dalal, M. Dahiya, and D. Kumar, J. Mater. Sci. Mater. Electron. 31, 13796 (2020).

44. G. Blasse, Phys. Lett. A 28, 444 (1968).

45. L. Cheng, X. Li, J. Sun, H. Zhong, Y. Tian, J. Wan, W. Lu, Y. Zheng, T. Yu, L. Huang, H. Yu, and B. Chen, Phys. B Condens. Matter 405, 4457 (2010).

46. S. Devi, A. Khatkar, V. B. Taxak, M. Dalal, S. Chahar, J. Dalal, and S. P. Khatkar, J. Alloys Compd. 767, (2018).

47. H. Dahiya, M. Dalal, A. Siwach, M. Dahiya, and D. Kumar, J. Mater. Sci. Mater. Electron. 29, 20750 (2018).

48. A. K. Vishwakarma, K. Jha, M. Jayasimhadri, B. Sivaiah, B. Gahtori, and D. Haranath, Dalt. Trans. 44, 17166 (2015).

49. P. Sehrawat, A. Khatkar, S. Devi, A. Hooda, S. Singh, R. K. Malik, S. P. Khatkar, and V. B. Taxak, Chem. Phys. Lett. 737, 136842 (2019). 
Figures

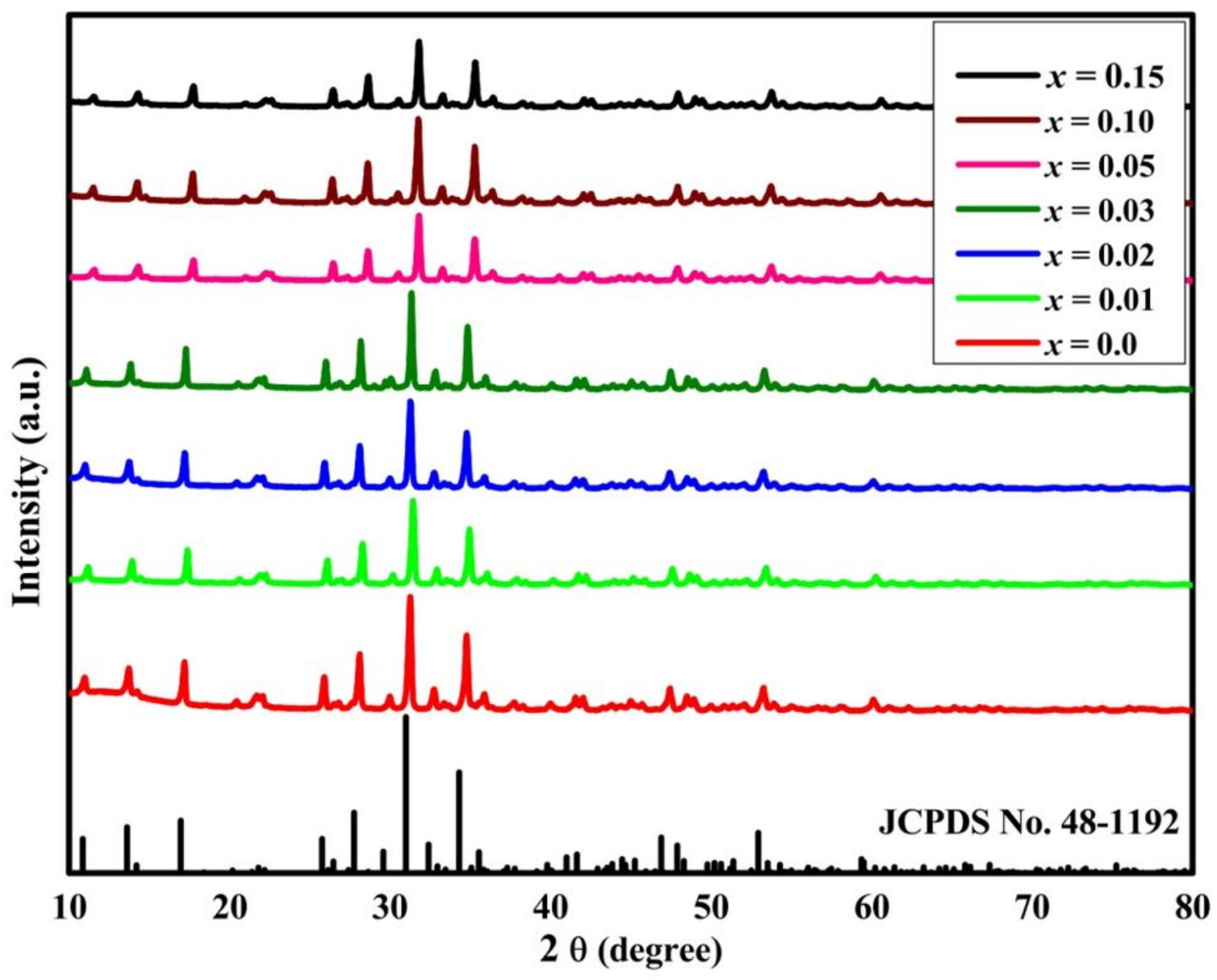

Figure 1

XRD profile of Ca9DyxAI(1-x)(P04)7 $(x=0-0.15 \mathrm{~mol})$ with the standard JCPDS data. 


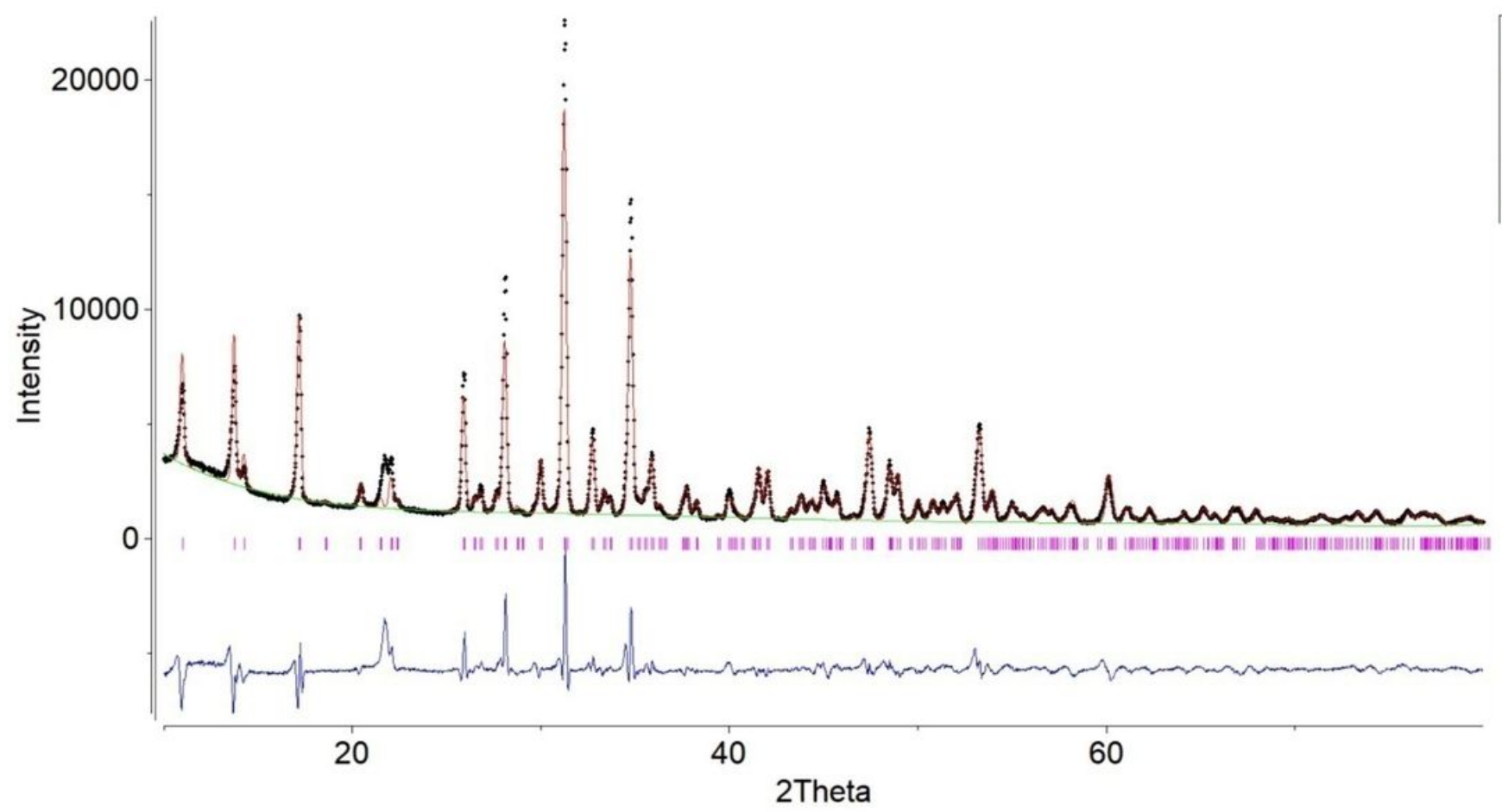

Figure 2

Rietveld refinement of Ca9Dy0.03Al0.97(PO4)7 nanophosphor with refinement parameters $\chi 2=2.3$, $\mathrm{wRp}(\%)=12.23$, and $\operatorname{Rp}(\%)=9.14$.

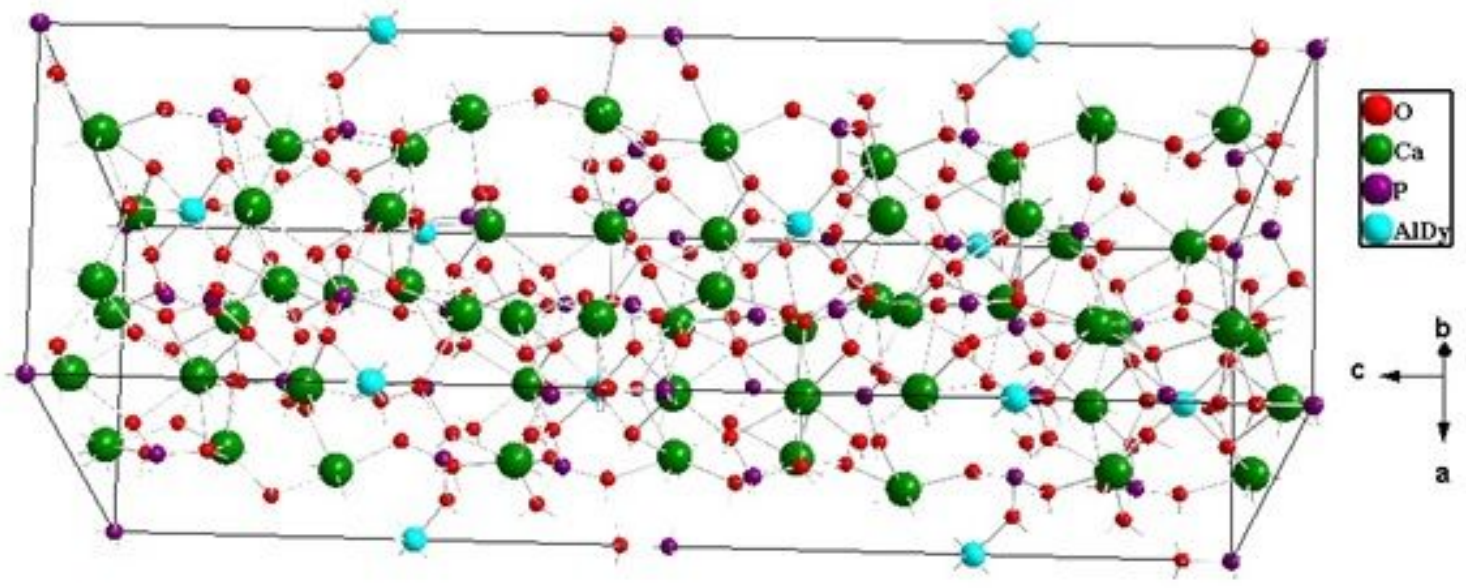

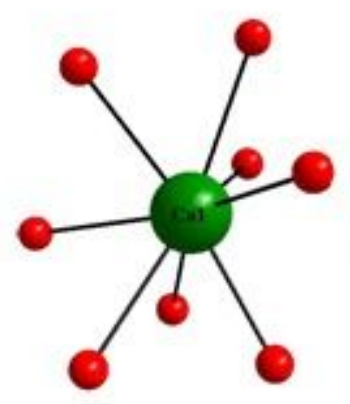

Cal

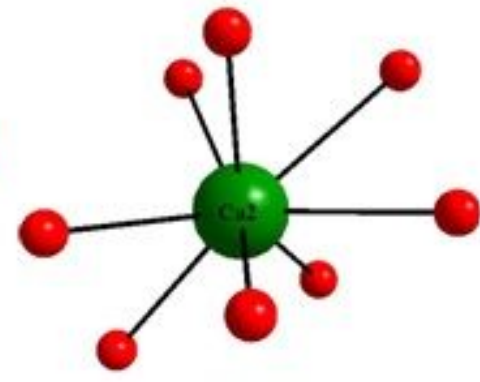

$\mathrm{Ca} 2$

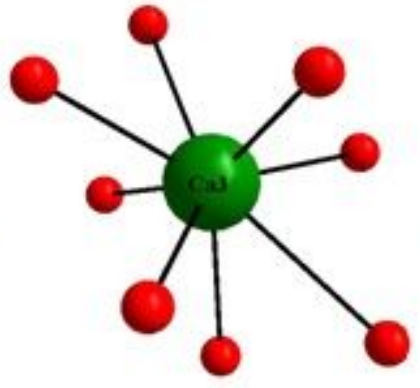

$\mathrm{Ca} 3$

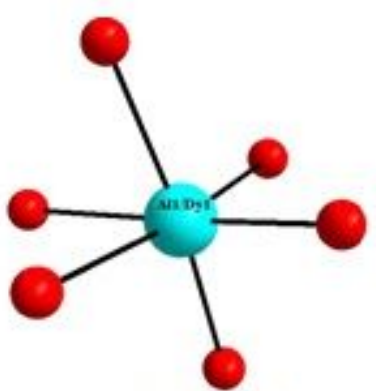

All/Dyl 


\section{Figure 3}

The crystal lattices view of Ca9Dy0.03Al0.97(PO4)7 nanophosphor along with the coordination environment of different cations.

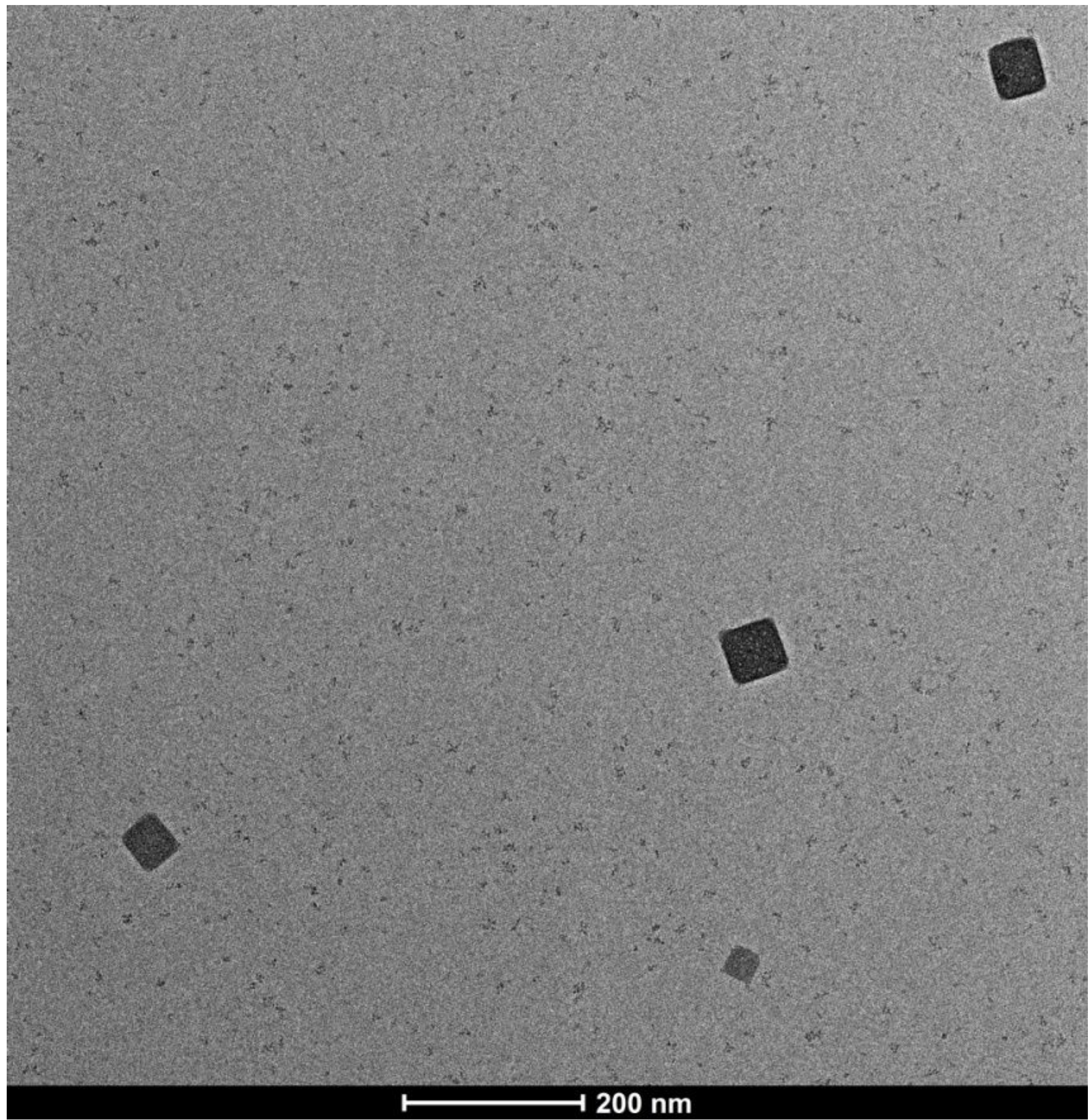

\section{Figure 4}

TEM micrograph of Ca9Dy0.03Al0.97(PO4)7 calcined at $1100{ }^{\circ} \mathrm{C}$. 


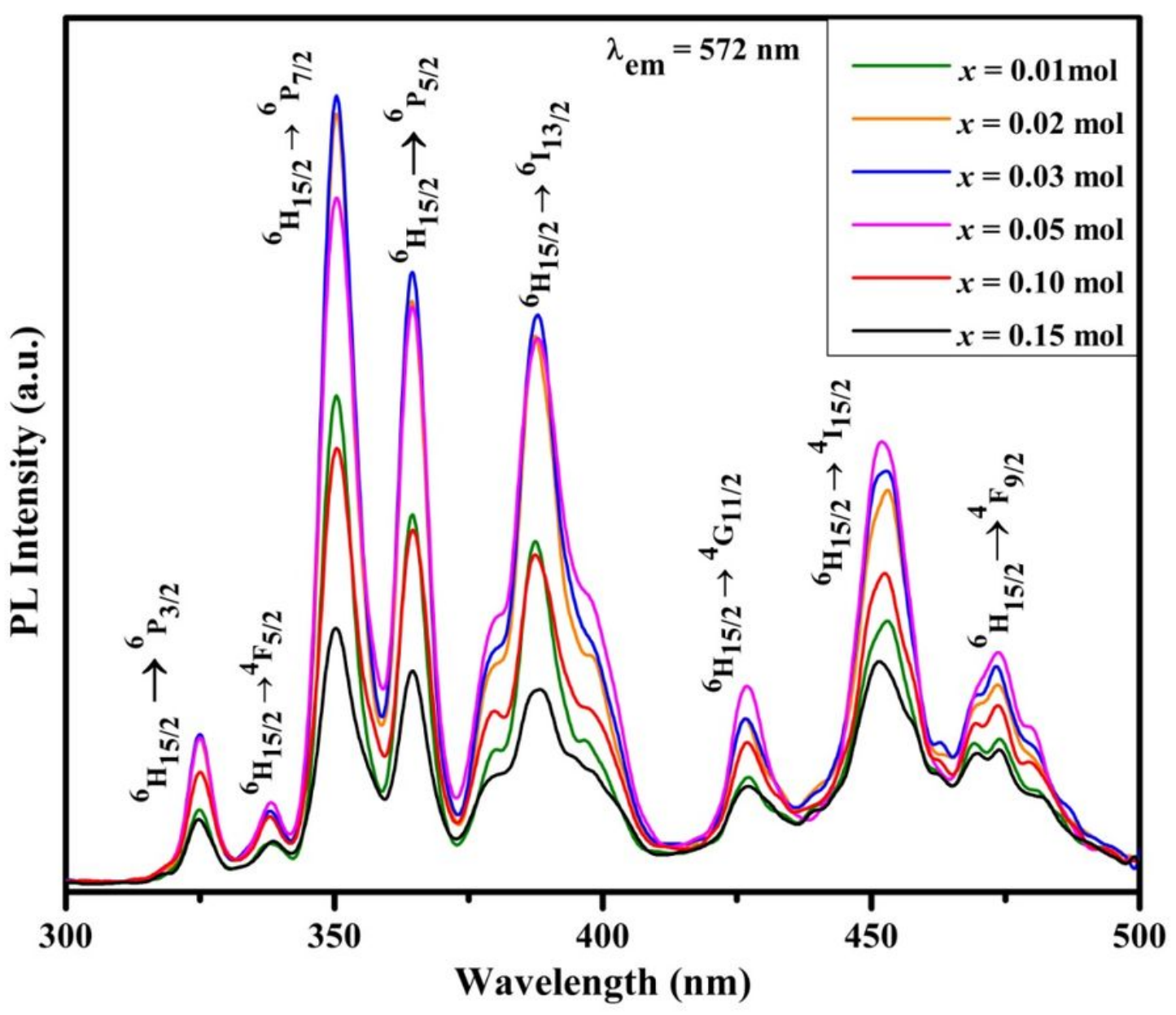

Figure 5

$\mathrm{PL}$ excitation spectra of Ca9DyxAl$(1-\mathrm{x})(\mathrm{PO} 4) 7(\mathrm{x}=0.01-0.15 \mathrm{~mol})$ nanophosphors recorded at $\lambda \mathrm{em}=$ $572 \mathrm{~nm}$. 


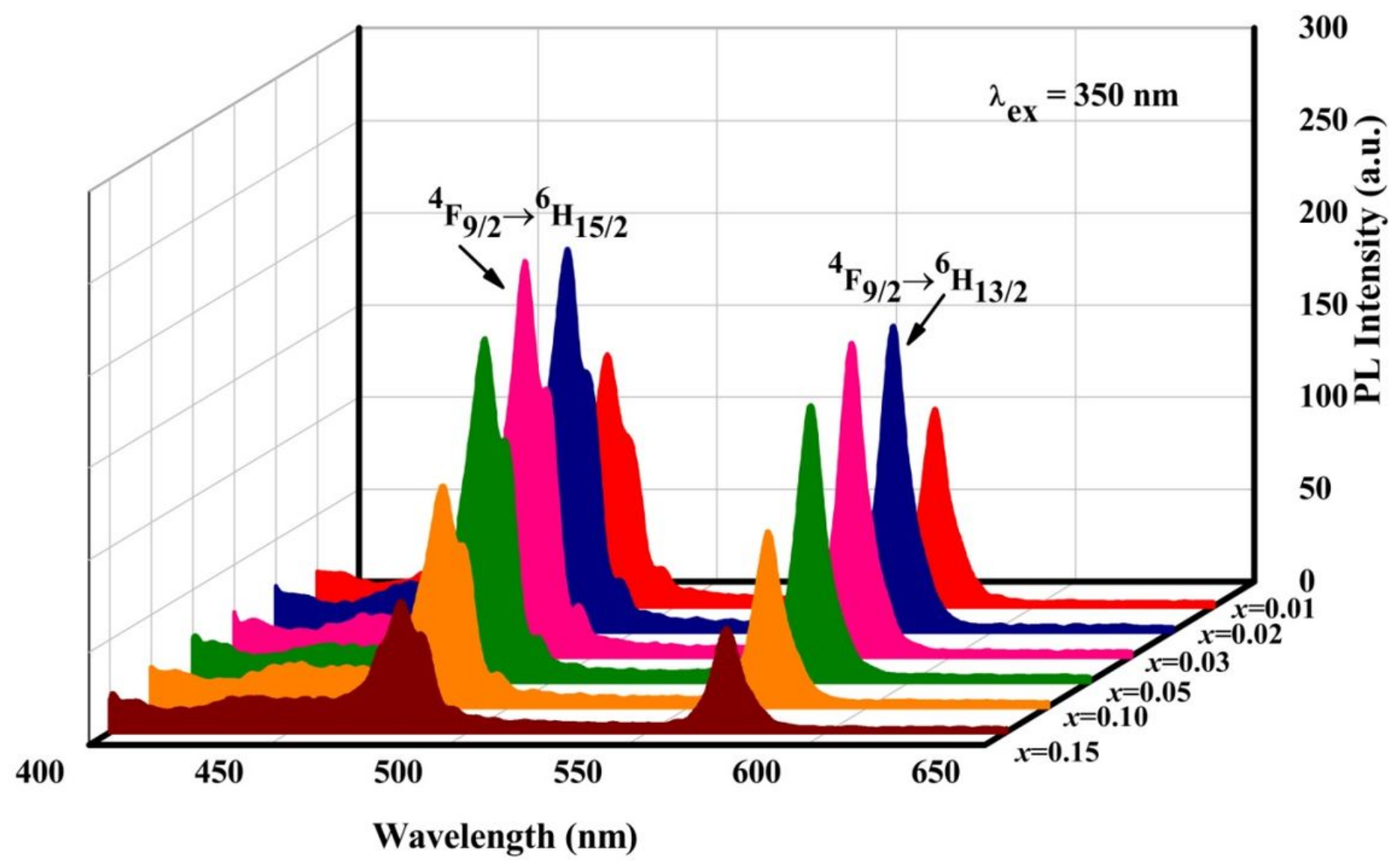

Figure 6

PL Emission spectra of Ca9DyxAl(1-x)(P04)7 $(x=0.01-0.15 \mathrm{~mol})$ nanophosphors recorded at $\lambda \mathrm{ex}=350$ $\mathrm{nm}$. 


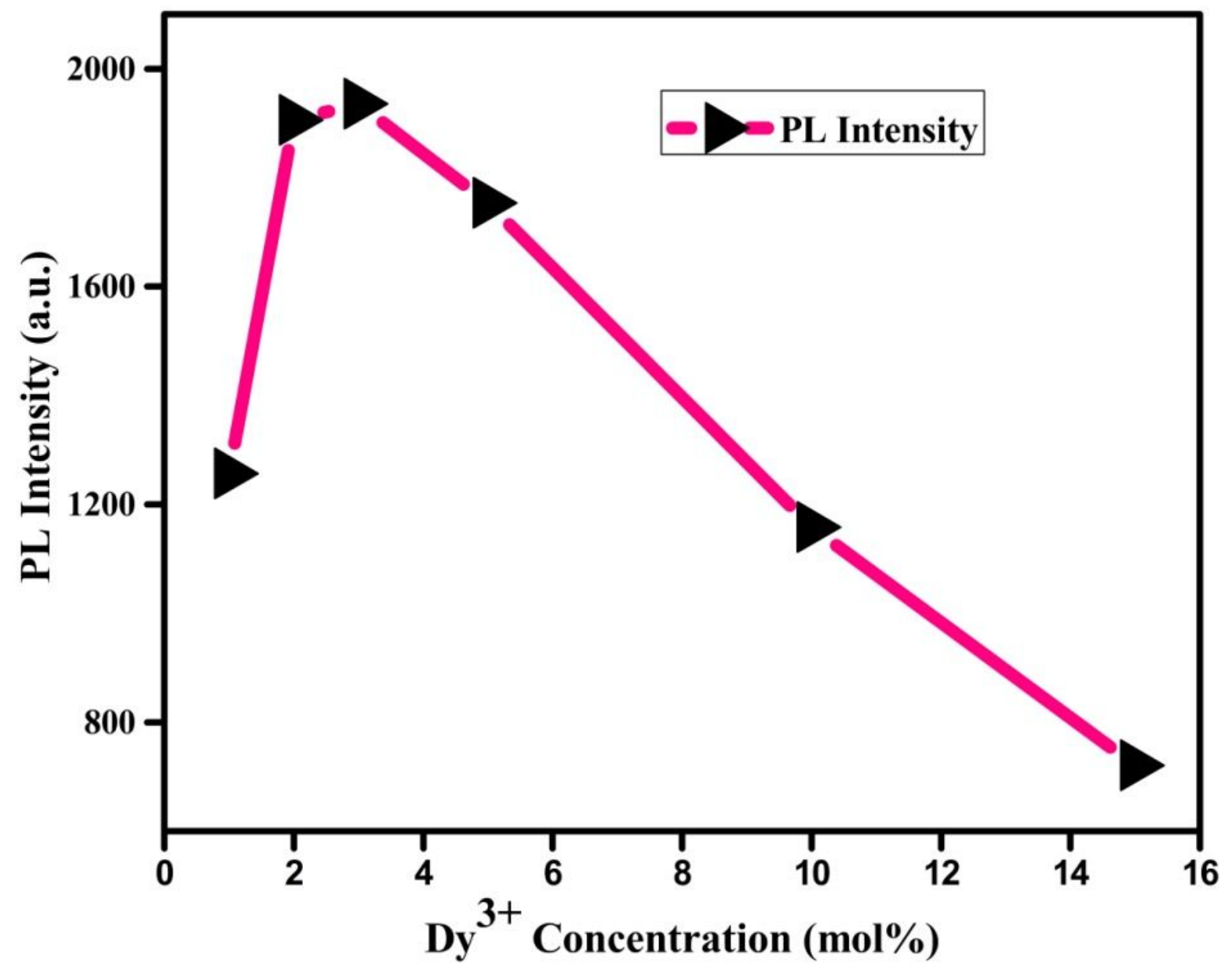

Figure 7

Variation of PL emission intensity as a function of Dy3+ concentration in Ca9Al(PO4)7: $x$ Dy3 + $(x=0.01-$ $0.15 \mathrm{~mol})$ nanophosphors. 


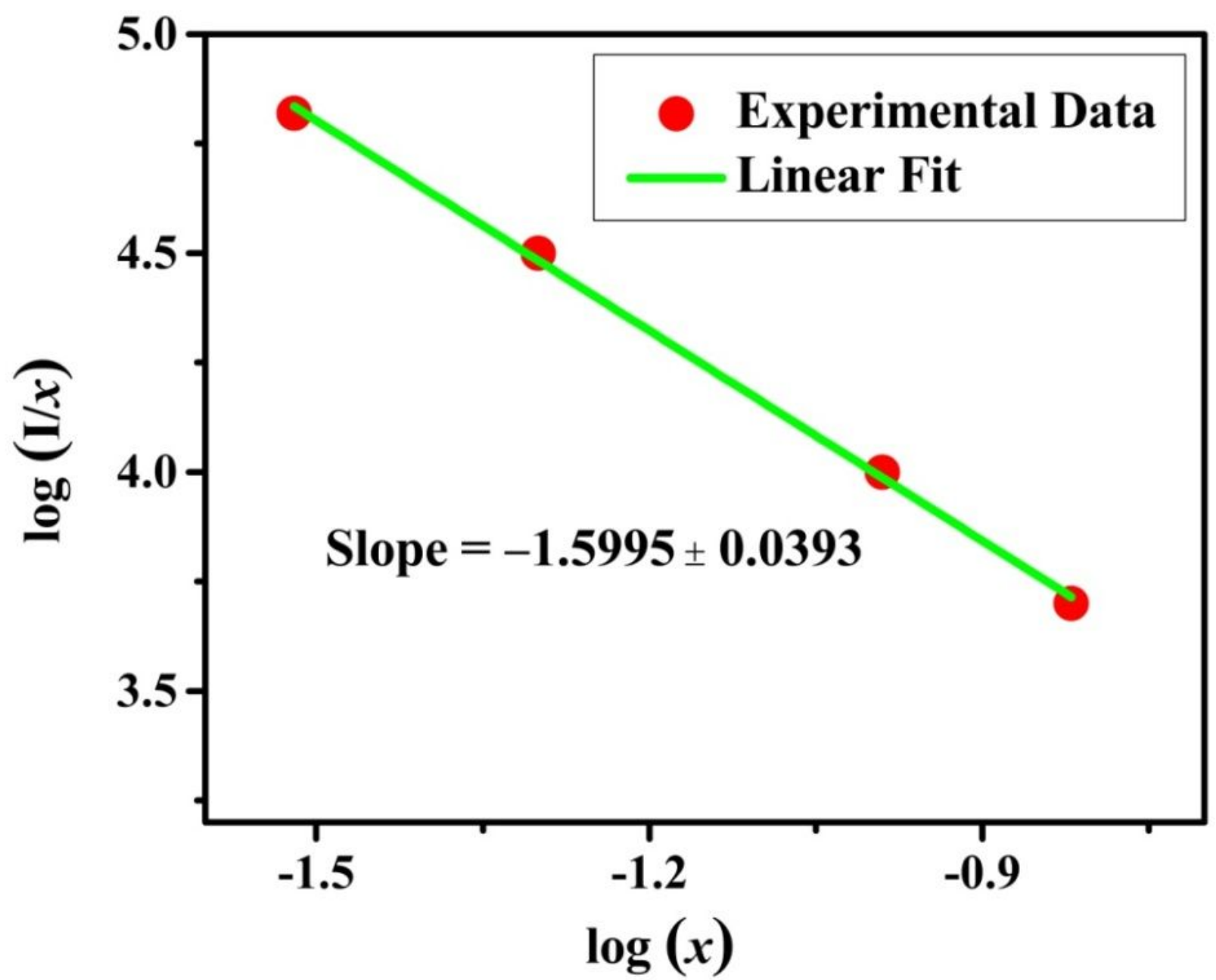

Figure 8

Plot of $\log (1 / x)$ as a function of $\log (x)$ in Ca9Al(PO4)7 : Dy3+ nanophosphors. 


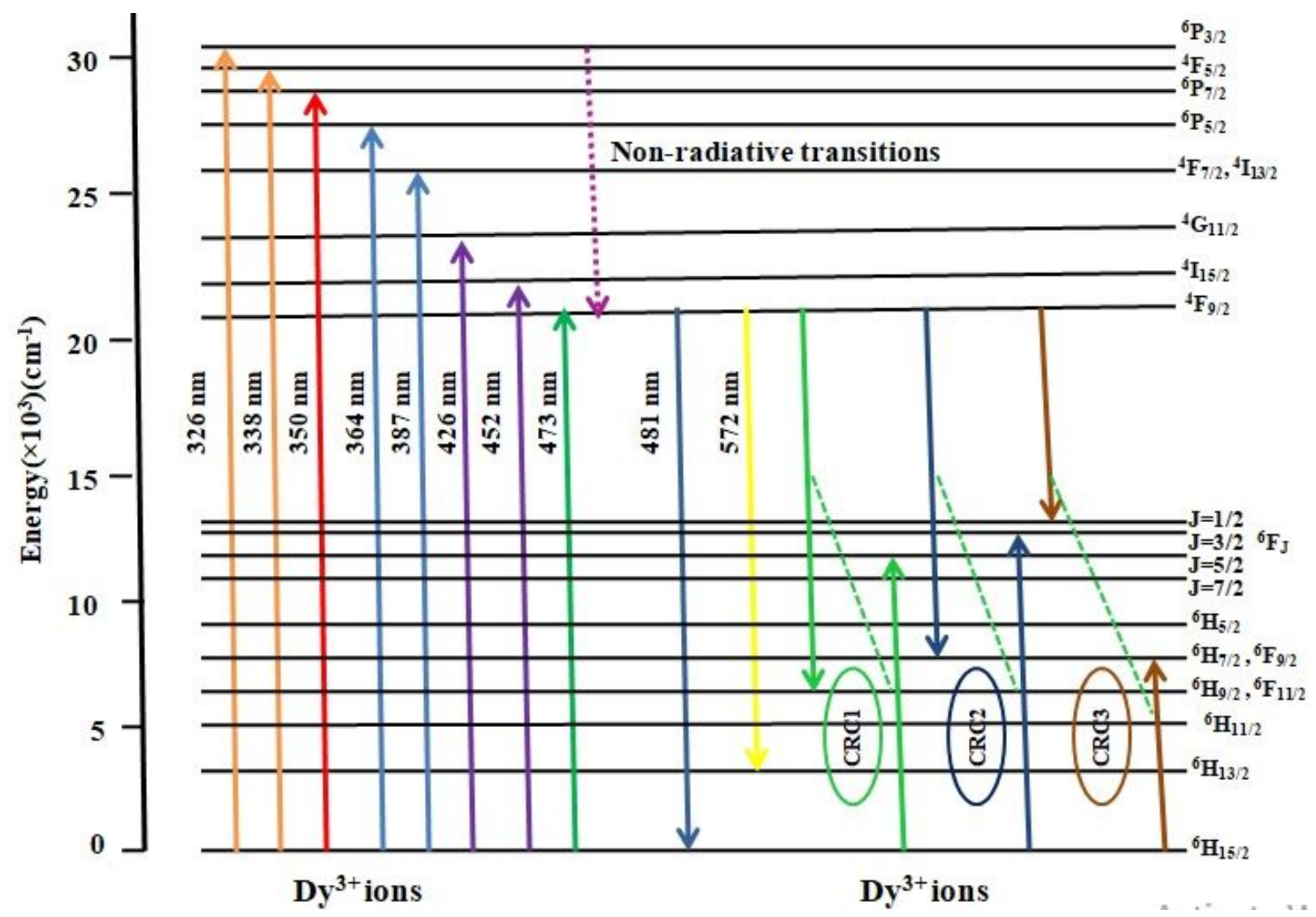

Figure 9

Schematic energy transfer mechanism of Dy3+ ions for Ca9Al(P04)7:Dy3+ nanophosphors. 


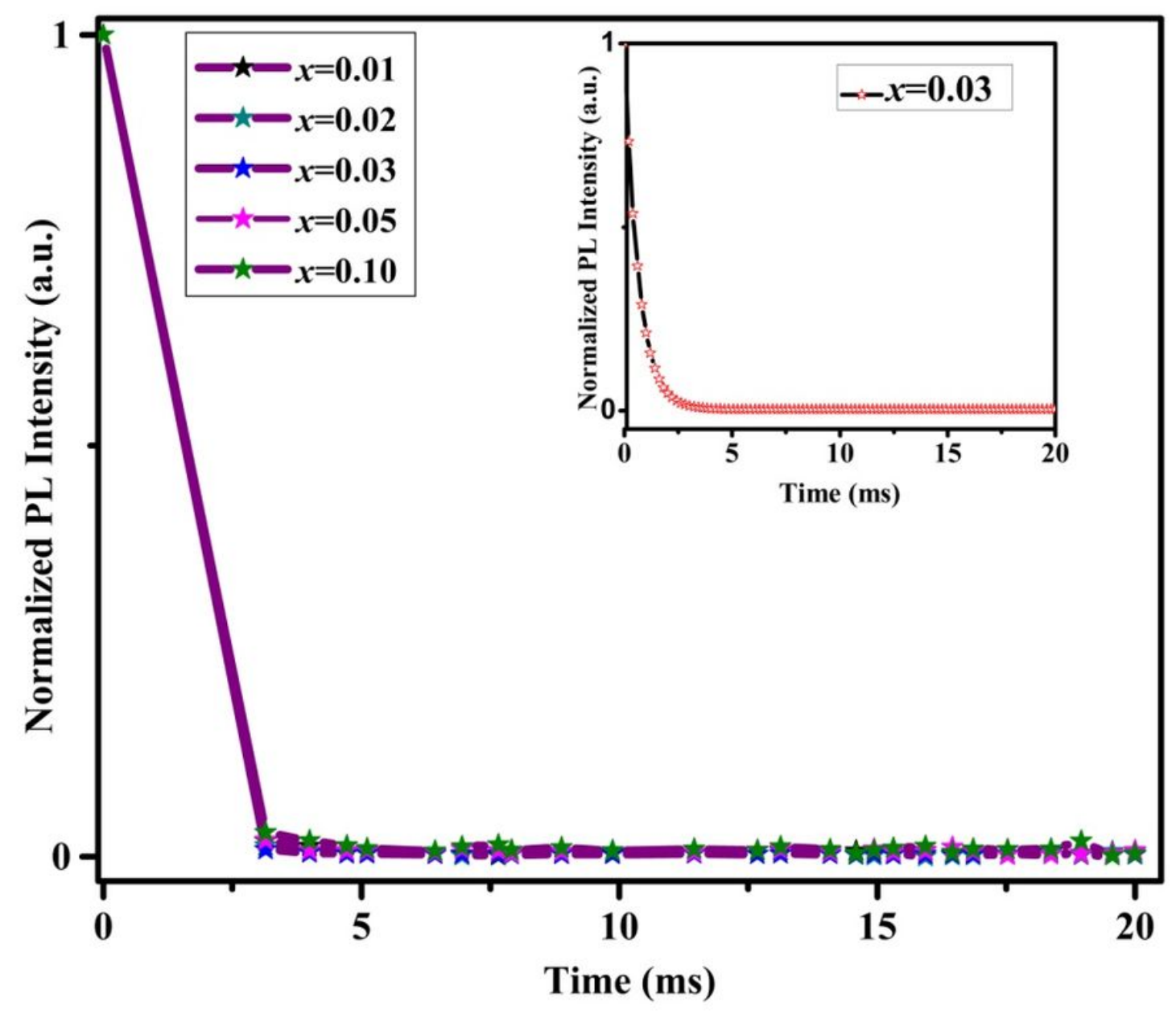

Figure 10

The luminescence decay curves for the emission of Ca9DyxAl(1-x)(P04)7 ( $x=0.01-0.10 \mathrm{~mol})$ nanophosphors. 


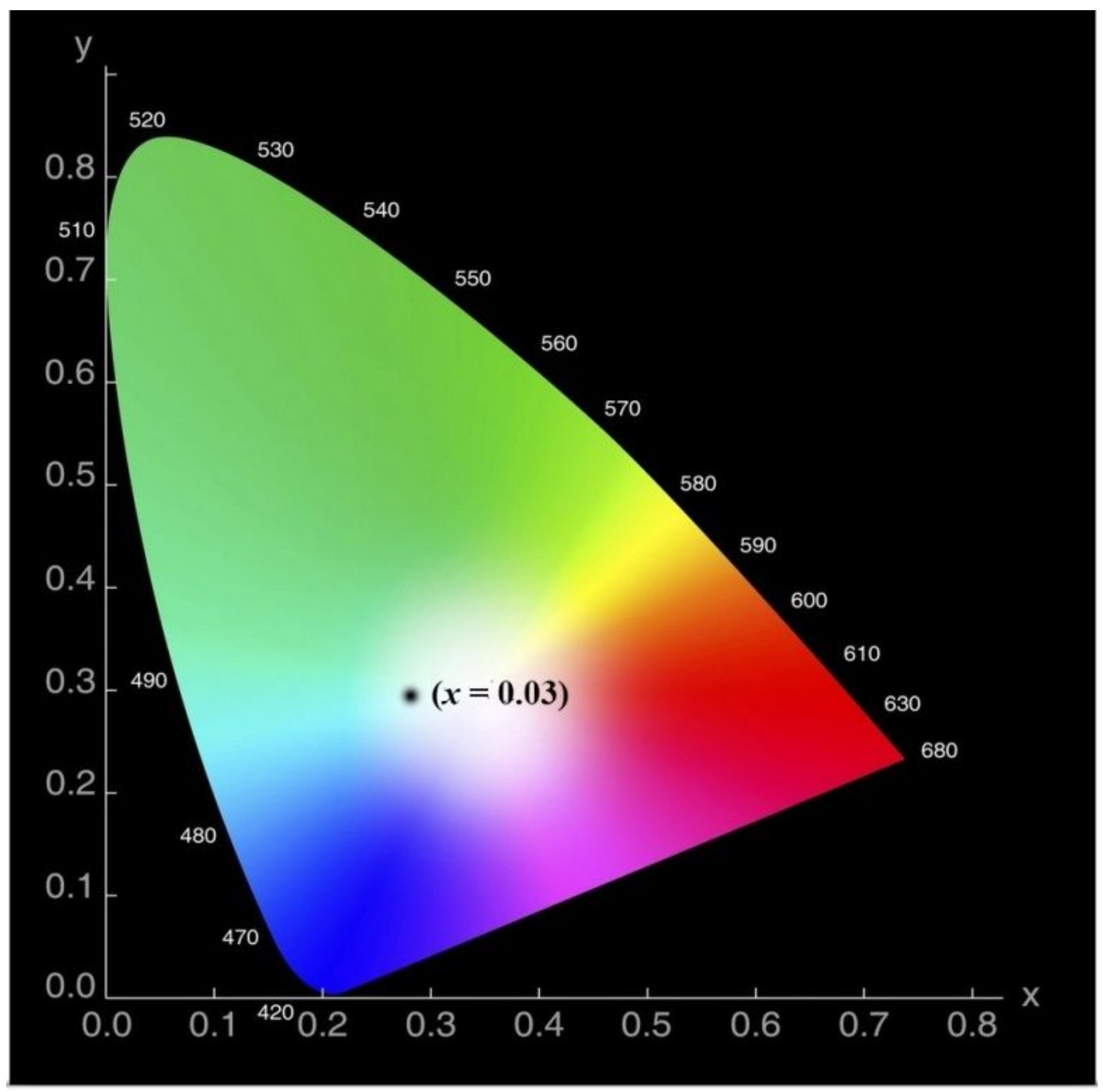

\section{Figure 11}

CIE1931 chromaticity diagram of the synthesized Ca9Dy0.03Al0.97(P04)7 nanophosphor. 


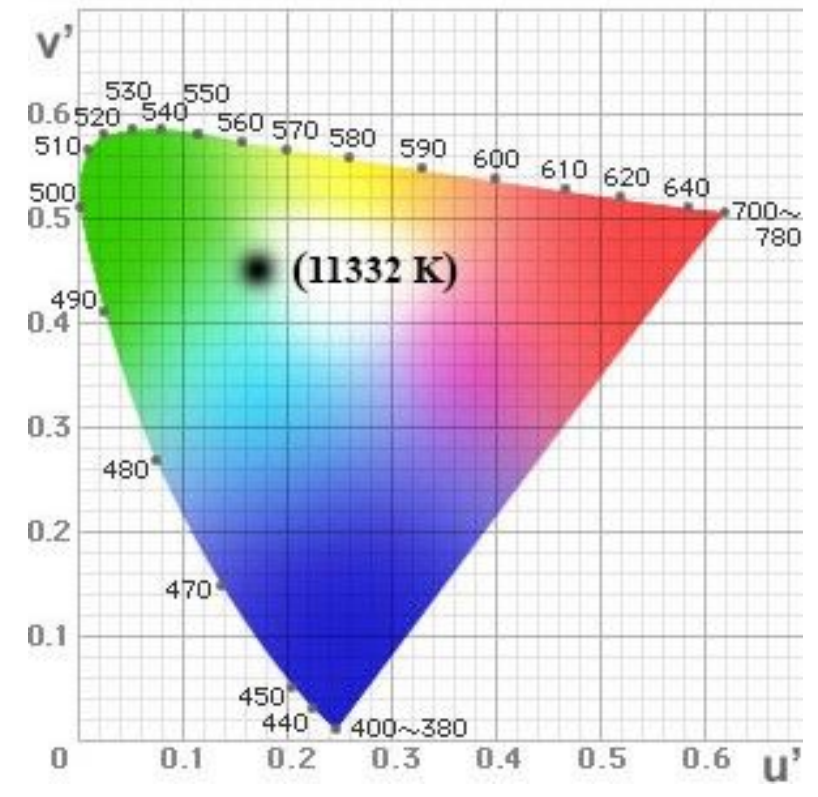

Figure 12

CCT diagram of Ca9Dy0.03Al0.97(PO4)7 nanophosphor.

\section{Supplementary Files}

This is a list of supplementary files associated with this preprint. Click to download.

- ResearchHighlights.docx

- graphicalabstract.jpg 